\title{
The Employees' Organizational Commitment Impact on Organizational Change - The Introduction of New Work Strategy
}

\author{
Sulaiman Tahajuddin* \\ Senior Lecturer, Faculty of Business Economics and Accountancy, Universiti Malaysia Sabah, Kota Kinabalu, \\ Malaysia \\ *Corresponding author: sulaiman@ums.edu.my
}

\begin{abstract}
With the advent of new technology, globalization, global and regional financial economic distress, the pressure from the stakeholders, market competition and many others, have greatly affected many nations, institutions and organizations around the globe to change for many reasons. This paper attempts to shed light on the impact of employees' organizational commitment to organizational change which is caused by the introduction of new work environment and strategy. A quantitative method was employed and the data was collected through questionnaires involving employees from different ranks in the Royal Malaysian Police in Labuan Branch, Sabah, Malaysia. Through quantitative analysis using SPSS, the findings reveal that there is a strong significant relationship between employees' organizational commitment to organizational change. Being aware of the limitations in this study, it is recommended that future research to look at other influencing factors affecting organizational change such as work autonomy, leadership style etc. At the same time, looking from different research method such as qualitative approach will as well enrich the understanding of this social phenomenon.
\end{abstract}

Keywords: Organizational change, Organizational commitment, Strategy.

\section{Introduction}

The main focus of this research is to explore the relationship between the employees' organizational commitment and the perceived success of organizational change initiative at the organizational level. Apart from the organizational commitment, this topic will also provide an insight of the reasons and factors triggering or instigating any organization to pursue for change. Royal Malaysian Police (RMP) was established on 25 March 1807, relatively far older then the federation of Malaysia herself. The establishment of RMP is governed under the Police Act 1967. The functions and responsibilities of the RMP are clearly laid down in Section 3 (3) of the Police Act 1967. Despite the fact that the functions of RMP range from the general, right to the specific ones such as traffic control and security measures, their mere existence however is basically to ensure the national security and harmony is safely guarded and maintained.

Public sector reform has been a major concern not only in developed western countries but also in developing countries as well. Malaysia, as part of the developing countries in the South East Asian region is also not an exclusive case. [7] notes that there are two major factors that lead the reform in this regard; first, the growing demand by the stakeholders on the government's efficiency, effectiveness and accountability in managing financial matters [9]; and second, intended initiatives by the government to implement numerous market-based reforms to align the public sector competitiveness with the private sector which is generally known as the new public management - NPM. Royal Malaysian Police (RMP) in this respect, which is one of the government arms in Malaysia, has been indeed experiencing many forms of changes and transformations at all level of its organization.

Vast majority of the organization-based research (such as [11]; [2]; and 19) have argued that in order to well understand the organizational change concept, it is imperative that the understanding of what organization and change concept is well understood. [4] and [13] argue that an organization can be conceptualized as a mixture of intangible and tangible elements which they call as interpretive scheme, design archetypes, and sub-systems. Although they admit that their conceptual understanding and theory of what organization is all about is still at skeleton phase, they believe that their concept of organization is useful to be used as a comprehensive guideline to understand and do research on the organization. [14] defines organizational transformation as an organizational change which permits the organization to be in a better position through the process of learning from its past and surrounding experiences to compete effectively in its competitive environment. Whereas, [13] views change in this respect as any change that takes place within the organization. Within this concept, the author confines the introduction and implementation of the Community Policing Strategy by the RMP as the changes within the RMP itself.

As highlighted by [16], due to rapid development and modernization of Malaysia that comes along with the transformation, Malaysia has also been facing the implications for the changes in terms of social, economic, and the 
perceptions of the public [20].

[16] further argue that, the literature also shows that during the late 1990s and early 2000 has shown that the RMP was facing a bad experience where the statistics show that the crime rates were increased with respect to muggings, gang fighting, pick pocketing, alcohol and drug-related crime, curb crawlers, violent on-street theft, intimidation and threats and the increased in the property crime. This eventually has triggered the feeling of personal fear, anxiety, and insecure among the citizens. RMP in this case has experiences the changes of public perceptions towards their capability in performing their main function to safeguard and maintaining the country's internal security and harmony.

In respond to the this alarming situation and the negative perception and lack of trust that the police force receives from the general public, the Malaysian parliament has setup a royal commission called Independent Police Complain and Misconduct Commission (IPCMC) to investigate the allegations and evaluate the police force performance. It was reported that RMP is working too much on tackling the criminal cases instead of concerning and prioritize the public personal safety. As [16] highlight, this public perception has not just negatively affected the RMP but the Malaysian government as well. Consequently, the IPCMC has suggested that the community policing strategy to be implemented to increase the public support in crime prevention and also to create harmony environment in the country.

Royal Malaysian Police (RMP) has been undergoing numerous changes since its establishment whether directly and indirectly, planned and unplanned, in many forms at all level. Up to the present however, nothing much on study has been carried out to investigate this nature of change, which to the author's opinion is imperative in bringing the positive future changes of RMP.

Therefore, this paper attempts to highlight some of the problems statements that need to be considered in the RMP's community policing strategy. First, what are the factors to consider in ensuring the success of this newly reintroduced strategy? Second, to what extent the employees' organizational commitment really matter in ensuring the success of RMP's community policing strategy? Last but not the least, to what extent the success or failure of this community policing strategy has achieved. This research is tailored in such a way to answer to these interrelated questions or problem statements.

\section{Literature Review}

\section{A. The Concept of Organization}

[17] argue that an organization can be viewed from two different perspectives; (1) an organization is a 'social entity or structure (a thing or a noun) that retains its identity while changing from one state to another over time', and (2) an organization is 'simply a reification of a set of processes that maintain the organization by continuously structuring it and maintaining its boundaries in a field of other processes that are continuously breaking down the organization and its boundaries'.

[13] conceptualizes organization as one of the social entities that composes of three interrelated elements namely interpretive scheme, design archetype and sub-systems. According to Laughlin, these three element will co-exist harmoniously until the 'kick' or disturbance makes it 'responds' then adapts the change to 'reappear' in a new coherent unit. He also argues that change can exist in two forms, called first order change and second order change. First order change is a form of change that take place at the tangible (either at design archetype and subsystem, or any of them) elements of organization, but yet still maintaining the interpretive scheme. The second order change is more conclusive where the change is taking place at all three elements and long lasting. This type of change occurs as a result of external pressure (change factors) such as politics, economic, war etc. in which the organization cannot avoid but to adapt and respond to change.

\section{B. The concept of Organizational Change}

Vast majority of the organization-based research (such as [11]; [2]; and [19] have argued that in order to well understand the organizational change concept, it is imperative that the understanding of what organization and change concept is well understood.

For example, the definition given by [18] suggest that the meaning of (organizational) change is 'a learning methodology to understand how environmental factors shape internal processes within organizations. Important questions concern how this interaction happens, what factors are influential, why change is fast or slow, how organizational members react to such change and how change impacts on the social and economic well-being of a society'. This definition is basically based on the critical perspective of management accounting which is concerned primarily with the contextual element of management control systems which take into consideration the interaction of the external environmental factors and internal processes of the organization towards the production of organizational change as the final result. Some theorists have also defined the change by contextualizing it with the space and time. For example, [3] define organizational change as 'a transformation of an organization between two points of time'. The definition barely means that change can be defined by clarifying the contexts (what things are changed) and the process (how these things are changed over time) dimensions of organizational change. [14] defines organizational transformation as an organizational change which permits the organization to be in a better position through the process of learning from its past and surrounding experiences to compete effectively in its competitive environment.

Considering that the organization can be viewed as a social entity that is formed from interrelated intangible and tangible elements that can influence each other from and to any directions [13], it so true that the success of the organizational change will need to depend on many factors, and cannot be 
treated in isolation [5].

\section{Reasons for Organizational Change}

There are many reasons or justifications have been put forward to rationalize why an organization experiences change [8]. As argued [1], the change can take place at the micro level (such as organization or units in organization) and macro level (the state or country level).

For example, [10] identified three major broad points of view which argue the reasons why organizations change. The first view holds that an organization is just like a natural living thing where the old organization will perish, and subsequently replaced by a new one. The second view suggests that organizations need to adapt change in order to respond to the environmental changes, threats and opportunities. The third view which suggests that organizations need to change mainly to respond to 'endogenous processes', but that changes are less attributed to the desires of the key role actors and the environment's changes.

\section{Organizational Commitment}

Basically, this research will embrace the definition of employees' organizational commitment as the relative strength of an individual's identification with and involvement in a particular organization.

A specific example of the study carried out by [15] strongly supports the hypothesis that employees' organizational commitment is significantly correlated to the organizational change. [15] study reveals that organizational change in the form of strategy implementation, individual learning and improvement in organizational performance is significantly correlated with the organizational commitment through the its determinants in the form of employees role of autonomy, the employee-manager relationship, job motivation and the fitness of change initiatives and the employees' or department's vision for change. In particular, [15] argue that organizational commitment in the form of Affective and Normative, and not Continuous, are strong predictor of organizational change. Therefore, the following hypothesis is proposed in this study:

\section{H1 Employee's organizational commitment has a significant positive relationship with organizational change.}

\section{Methodology}

This research attempts to investigate the relationship of the employee's organizational commitment and the organizational change at RMCD of Malaysia. In doing so, the author employs the quantitative approach, based on the model developed by [15]. For this study, the author had attempted to get the response number not less than 200. In doing so, the questionnaires was sent either through mail with pre-stamped and returned address envelope, and by-hand as well to the respondents that can be reached in person. The follow up was done to ensure and encourage the respondents to participate in the surveys, as recommended by [6].
The data was primarily collected via the questionnaires that are built from the previous related works in the field such as [12] and [15]. One of the advantages of having questionnaires developed through this method is that the respondents can easily participate and understand in the process of responding to the questionnaires. The Statistical Package for Social Science (SPSS) version 22.0 was used to analyze the data based on the several merits as argued by [12]. For this study, the author had attempted to get the response number not less than 200. In doing so, the questionnaires were sent either through mail with prestamped and returned address envelope, and by-hand as well to the respondents that can be reached in person. The follow up was done to ensure and encourage the respondents to participate in the surveys, as recommended by [6] eventually, there were more than 250 questionnaires sent out to various ranks of RMP officers in Labuan Branch, Sabah. Eventually, 235 returned back and after the 'cleaning' only 222 were usable for further analysis.

\section{Findings and Analysis}

This part presents the elaboration of findings and analysis of the data. At the outset, the general overview of the respondents which includes the information on the characteristics such as the age, gender, total length of service in Malaysian RMP, and the length of service in the current position. Prior to the analysis of the regression and the correlations, the factor analysis testing and the reliability and results were presented. Having done with them, the correlations and regression analyses were carried out to evaluate the model that being conceptualized in the beginning of this current research endeavor.

The Hypothesis 1 of the study states that Organizational Employees' Work Commitment has a significant positive relationship with organizational Change.

Based on table 1, it can be said that the final variance is explain by 36.0 percent by the organizational work commitment, which is also significant as denoted by value of Sig. F Change of 0.000 .

Based on the findings that shown through table 1, the conclusion can be made that there is a strong positive significant relationship between the Employees' Work Commitment and the Perceived Success of Community Policing strategy $(\mathrm{B}=+0.600, \mathrm{p}<0.01)$. Therefore, $\mathrm{H} 1$ is supported.

Table 1

Employees Work Commitment to Perceived Success of Community Policing - Coefficients ${ }^{\mathrm{a}}$

\begin{tabular}{lll}
\hline $\begin{array}{l}\text { Dependent } \\
\text { Variable }\end{array}$ & Independent variable & $\begin{array}{l}\text { Std. Coefficients } \\
\text { Beta }(\boldsymbol{\beta})\end{array}$ \\
\hline $\begin{array}{l}\text { Perceived Success of } \\
\text { Community Policing }\end{array}$ & $\begin{array}{l}\text { Employees' Work } \\
\text { Commitment }\end{array}$ & $0.600^{* * *}$ \\
\hline & R2 & 0.360 \\
\hline & Adjust R2 & 0.357 \\
\hline & Sig. F & $114.792(\mathrm{p}<0.01)$ \\
\hline
\end{tabular}




\section{Discussion}

The discussion and justifications of the findings and analysis in the previous chapter will be presented by integrating the relevant and underlying theoretical and conceptual ideas pertaining to the findings and analysis. Following that, the topic will put forward the implications of this research's findings on the existing theoretical and empirical field of management, particularly in the area of employee's organizational commitment, organizational change, and the human resource management as well.

The main objective of this research is to examine and investigate the relationship between the influencing factors that contribute to the success of the organizational change initiative. In this research, the initiative by the Royal Malaysian Police to re-implement the Community Policing throughout the country is viewed by the researcher as one type of organizational change process and therefore the success is certainly relied on some underlying influential factors. In relation to the main objectives, the researcher believes that factor such as employees' organizational commitment is a vital element in ensuring the success implementation of the Community Policing initiative, which is the organizational change in this case.

[15] strongly supports the hypothesis that employees organizational commitment is significantly correlated to the organizational change, in this case the community policing strategy in Malaysia. [15] study reveals that organizational change in the form of strategy implementation, individual learning and improvement in organizational performance is significantly correlated with the organizational commitment through the its determinants in the form of employees role of autonomy, the employee-manager relationship, job motivation and the fitness of change initiatives and the employees' or department's vision for change. The findings of the current research demonstrates that there is a strong positive significant relationship between the employees organizational commitments to change, and therefore in line with the previous research's findings and arguments with regards to this particular matter.

\section{Conclusion}

The aim of this paper is to examine and highlight the relationship between the employees' organizational commitment with the perceived success of the community policing initiatives (the organizational change) that being practiced by the Royal Malaysian Police. Through the quantitative approach, it is demonstrated that there is a strong positive significant relationship between the employees' organizational commitments to change.

One limitation of this study that needs to be highlighted is the sampling technique. This research has only considered the samples in one particular location, namely the Federal Territory of Labuan, in Malaysia. This can possibly become a significant major limitation considering that the uniqueness of the contextual settings such as the location on the local work environment, the culture and the political situation might have a significant impact on the research findings and results.

\section{References}

[1] H. Ahmad, and H. M. Gelaidan, "Organizational Culture, Leadership Styles and Employee's Affective Commitment to Change: A Case of Yemen Public Sector," in Journal of Organizational Management Studies, vol. 20, no. 11, pp. 1-10, Oct. 2011.

[2] S. Barbara, and J. Fleming, "Organizational Change (Third Edition)". London: Prentice Hall. Feb. 2006.

[3] W. P. Barnett, and G. R. Carroll, "Modeling Internal Organizational Change," in Annual Review of Sociology, vol. 21, pp. 217-236, Aug. 1995.

[4] J. Broadbent, and R. Laughlin, "Developing Empirical Research: An Example Informed by a Habermasian Approach," in Accounting, Auditing \& Accountability Journal, vol. 10, no. 5, pp. 622-648, Dec. 1997.

[5] K. Cowan-Sahadath, "Business Transformation: Leadership, Integration and Innovation: A Case Study," in International Journal of Project Management, vol. 28, no. 4, pp. 395-404, May. 2010.

[6] D. Dillman, "Mail and telephone surveys: the total design method," New York: John Wiley \& Sons, Dec. 1978.

[7] M. K. Hassan, "Management Accounting and Organizational Change: An Institutional Perspective," in Journal of Accounting \& Organizational Change, vol. 1, no. 2, pp. 125-140, Jul. 2005.

[8] L. Gilson, S. Ellokor, U. Lehmann, and L. Brady, "Organizational change and everyday health system resilience: Lessons from Cape Town, South Africa," in Social Science \& Medicine, vol. 266, pp. 1 - 10, Dec. 2020.

[9] A. Goddard, "Accounting and NPM in UK Local Government Contributions towards Governance and Accountability," in Financial Accountability \& Management, vol. 21, no. 2, pp. 191-218, Apr. 2005.

[10] M. T. Hannan, and J. Freeman, "Structural Inertia and Organizational Change," in American Sociological Review, vol. 49, pp. 149-164, Apr. 1984.

[11] G. M. Hodgson, "Institutions and Individuals: Interaction and Evolution," in Organization Studies, vol. 28, no. 1, pp. 91-116, Jan. 2007.

[12] A. Ismail, H. A. B. Mohamed, A. Z. Sulaiman, M. H. Mohamad, and M. H. Yusuf, "An Empirical Study of the Relationship between Transformational Leadership, Empowerment and Organizational Commitment," in Business and Economics Research Journal, vol. 2, no. 1, pp. 89-107, Jan. 2011.

[13] R. Laughlin, "Environment Disturbances and Organizational Transitions and Transformations: Some Alternative Models," in Organization Studies, vol. 12, no. 2, pp. 209-232, Apr. 1991.

[14] K. L. Newman, "Organizational Transformation during Institution Upheaval," in Academy of Management Review, vol. 25, no. 3, pp. 602619, Jul. 2000.

[15] J. T. Parish, S. Cadwallader, and P. Busch, "Want to, need to, ought to: Employee Commitment to Organizational Change," in Journal of Organizational Change Management, vol. 21, no. 1, pp. 32-52, Feb. 2008.

[16] A. H. Sulaiman, J. Othman, B. A. Samah, A. Yero, J. L. D'Silva, and A. Ortega, "Determinants of Community Participation in Community Policing Program in Malaysia," in Journal of Applied Sciences, vol. 14, pp. 2439-2449, Jun. 2014.

[17] A. H. Van de Ven, and M. S. Poole, "Alternative Approaches for Studying Organizational Change," in Organization Studies, vol. 26, no. 9, pp. 13771404, Sept. 2005.

[18] D. Wickramasinghe, and C. Alawattage, "Management Accounting Change: Approaches and Perspective," Routledge, London and New York, Jun. 2007.

[19] N. M. Wijnberg, "Innovation and Organization: Value and Competition in Selection Systems," in Organization Studies, vol. 25, no. 8, pp. 1413 1433, Oct. 2004.

[20] A. Yero, J. Othman, B. A. Samah, J. L. D'Silva, and A. H. Sulaiman, "ReVisiting Concept and Theories of Community Policing," in International Journal of Academic Research, vol. 4, pp. 21-55, Jul. 2012. 